GENERASI EMAS

Jurnal Pendidikan Islam Anak Usia Dini

Vol. 01 No. 02, Oktober 2018

\title{
MULTIPLE INTELLIGENCES ANAK USIA DINI MENURUT AL-QUR'AN SURAT LUQMAN AYAT 12-19 (Kajian Filsafat Pendidikan)
}

\author{
NURHADI \\ Sekolah Tinggi Agama Islam (STAI) Al-Azhar, Pekanbaru \\ hadiaksi71@gmail.com
}

\begin{abstract}
Multiple Intelligence and spiritual, emotional and intellectual intelligence in the study of Islamic education philosophy are called Imaniyah, Amaliyah and Fikriyah intelligence. This term the author (researcher) concludes from Islamic history about the intelligence of the servants of the Shari'a bearers (the Prophets and the Apostles), the intelligence of the companions of the Prophet and the Messenger of Allah and the intelligence of the ulama (mujtahid fiqh). In Surah Luqman verses 12-19, it contains the subjects of Faith, Aqeedah, Tawheed is Ottoman intelligence. Thanks to Allah Almighty, Prayers, Devotion to Parents is Amaliyah's intelligence. Responsible, Tolerance, Patience, Tawaduk, Amar Ma'ruf, Nahi Mungkar, Ta'at Ibadah are Intellectual intelligence. In accordance with their nature, even though early childhood children are required to receive comprehensive teaching on multiple intelligences because early childhood is naturally fit, therefore parents as teachers must first express that intelligence to their children. In order to wake up and be aware of the potential of our human beings as a servant of Allah SWT. Because early childhood is a golden age for children for the revival of the soul of the afterlife world.
\end{abstract}

Keywords: Multiple, Intelligences, PAUD, Al-Qur'an, Luqman 12-19.

\section{PENDAHULUAN}

Islam adalah agama yang
sempurna mencakup segala aspek
kehidupan manusia. Hal ini sesuai
dengan kitab alquran agama Islam yang
merupakan kitab penyempurna bagi
kitab-kitab agama terdahulu. Ini juga
diwahyukan kepada Nabi dan Rasul yang
paling sempurna (Nurhadi, 2018: 2).

Surah al-Maidah ayat 3 menyinggung hal ini:

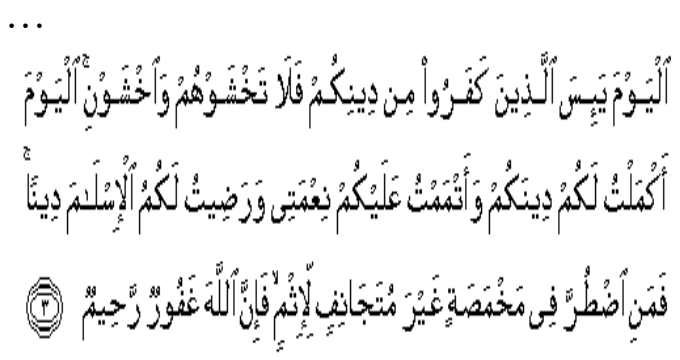

Artinya:

... Pada hari ini orang-orang kafir telah putus asa untuk 
GENERASI EMAS

Jurnal Pendidikan Islam Anak Usia Dini

Vol. 01 No. 02, Oktober 2018

(mengalahkan) agamamu, sebab itu janganlah kamu takut kepada mereka dan takutlah kepada-Ku. Pada hari Ini Telah Kusempurnakan untuk kamu agamamu, dan Telah Kucukupkan kepadamu nikmat-Ku, dan Telah Ku-ridhai Islam itu jadi agama bagimu (Depag RI, 2015:157).

Menilik ayat di atas, maka tanpa terkecuali masalah pendidikan dan lebih spesifik lagi adalah Pendidikan Anak Usia Dini (PAUD).

Pendidikan adalah upaya mewariskan nilai-nilai yang akan menjadi penolong dan penentu dalam menjalani kehidupan sekaligus untuk memperbaiki nasib dan peradaban umat manusia. Maju-mundurnya atau baik buruknya peradaban masyarakat suatu bangsa akan ditentukan oleh bagaimana pendidikan yang dijalani (Mansur, 2002). Tujuan pendidikan yang ideal adalah peningkatan keseimbangan berbagai aspek atau potensi yang ada (Wahyuni, 2018: 51).

Pendidikan memiliki makna yang sangat penting dalam menyiapkan manusia Indonesia seutuhnya, membangun masa depan anak-anak dan masyarakat Indonesia seluruhnya.
Pendidikan hendaklah dilakukan sejak anak berusia dini yang dapat dilakukan oleh orang dewasa, baik orang tua maupun guru sebagai tenaga pendidik di lembaga formal (Raihana, 2018: 17). Pendidikan Islam tentang kajian dan pengembangan anak usia dini, dikenal rumpun keilmuan Pendidikan Islam Anak Usia Dini. Pendidikan Islam Anak Usia Dini merupakan upaya disiplin ilmu untuk membentuk calon-calon pendidik mengetahui, memahami, dan menerapkan nilai-nilai pendidikan Islam terhadap anak usia dini dan lingkungan pendidikan, baik dalam pendidikan formal, maupun pendidikan non-formal. Dalam proses pendidikan anak usia dini, diperlukan pendekatan keislaman (Darajat, 2009: 29; Hidayat, 2018: 29).

Pendidikan sejak dini akan memberikan tanaman yang akarnya dalam sanubari. Perkembangan pada anak usia dini ditandai dengan aspek perkembangan morality heteronomy, tetapi pada usia sepuluh tahun akan beralih ke suatu tahap yang perkembangannya lebih tinggi yang disebut dengan morality otonomy (Mansur, 2015; Wahyuni, 2018: 51). Berdasarkan UU RI Nomor 20 Tahun 


\section{GENERASI EMAS}

Jurnal Pendidikan Islam Anak Usia Dini

Vol. 01 No. 02, Oktober 2018

2003 Pasal 1 (Hasbullah, 2010: 4), pendidikan diartikan sebagai usaha sadar dan terencana untuk mewujudkan suasana belajar dan proses pembelajaran agar peserta didik secara aktif mengembangkan potensi dirinya untuk memiliki kekuatan spiritual kegamaan, pengendalian diri, kepribadian, kecerdasan, akhlak, mulia, serta ketrampilan yang diperlukan dirinya, masyarakat, bangsa dan negara (Raihana, 2018: 17; Darajat, 2009: 20).

Dewasa ini, banyak fenomena memprihatinkan terjadi dalam masyarakat, hal-hal yang tidak sepantasnya dilakukan justru dilakukan oleh anak-anak, seperti yang dapat diketahui dalam tayangan televisi maupun media cetak, bahwa anak sekarang sedang mengalami penurunan bahkan pemerosotan moral yang sangat pesat. Seorang anak menganiaya teman sebayanya di sekolah sampai meninggal, seorang anak yang berani menyiksa bahkan membunuh orangtuanya sendiri. Bukan hanya hal itu saja, mereka tidak punya rasa hormat terhadap orang yang lebih tua, dengan mudah ikut terjerumus dalam pergaulan yang tidak sewajarnya, seperti membolos sekolah, bertengkar pribadi maupun tawuran antar sekolah, menonton video porno pun ada yang melakukannya, minum minuman keras, dan mengonsumsi narkotika, serta melakukan hubungan seks pranikah, akibatnya terjadi perkawinan dini, kehamilan di luar nikah dan aborsi (Seyaningrum, 2015: 1).

Anak adalah harapan masa depan, yang kelak akan menjadi penerus bangsa dan negara. Oleh karena itu, perlu dipersiapkan agar kelak menjadi sumber daya manusia yang berkualitas, sehat, bermoral dan berbudi luhur (Hasan, 2011: 130). Agama Islam menjelaskan bahwa anak adalah amanah (titipan) Allah SWT, yang harus dijaga, dirawat, dan dipelihara dengan sebaik-baiknya oleh setiap orang tua. Sejak lahir anak memiliki potensi yang harus dikembangkan sebagai penunjang kehidupannya di masa depan (Ningrum, 2018: 1; Fadlillah \& Mualifatu, 2014: 44). Dengan bekal itu kemudian anak belajar; mula-mula melalui hal-hal yang dapat diindra dengan menggunakan panca indranya sebagai jendela pengetahuan (Muhaimin, 2004). Selanjutnya bertahap dari hal-hal yang dapat diindra kepada yang abstrak, dan 


\section{GENERASI EMAS}

Jurnal Pendidikan Islam Anak Usia Dini

Vol. 01 No. 02, Oktober 2018

dari yang dapat dilihat kepada yang dapat

dipahami. Setelah dilahirkan manusia mulai memasuki proses belajar melalui interaksi dengan lingkungannya, baik sosial maupun fisik (Seyaningrum, 2015:

2). Sebagaimana hadist Nabi Muhammad SAW:

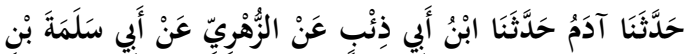

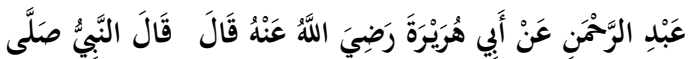

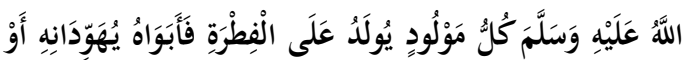

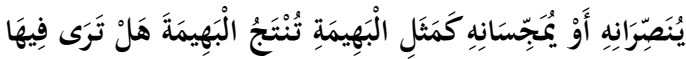
جَدْعَاءَ
Telah menceritakan kepada kami Adam telah menceritakan kepada kami Ibnu Abu Dza'bi dari AlZuhriy dari Abu Salamah bin 'Abdurrahman dari Abu Hurairah radliallahu 'anhu berkata; Nabi SAW bersabda: "Setiap anak dilahirkan dalam keadaan fithrah. Kemudian kedua orang tunyalah yang akan menjadikan anak itu menjadi Yahudi, Nashrani atau Majusi sebagaimana binatang ternak yang melahirkan binatang ternak dengan sempurna. Apakah kalian melihat ada cacat padanya?" (HR. Bukhari No. 1296).

Artinya:

Tabel 1. Penguatan dengan 16 hadis dalam riwayat lain menurut kutub al-Tis'ah

\begin{tabular}{|c|c|c|c|c|}
\hline No & No Hadis & Perawi & Judul dalam Kitab Hadis & Teks Naskah Arab Kitab Hadis \\
\hline 1 & 6525 & Bukhari & $\begin{array}{l}\text { Menakwilkan mimpi setelah } \\
\text { shalat subuh }\end{array}$ & تعبير الؤويا بعد صلاة الصبح \\
\hline 2 & 4091 & Abu Daud & $\begin{array}{l}\text { Penjelasan tentang keturunan } \\
\text { orang-orang Musyrik }\end{array}$ & في ذراري المشركين \\
\hline 3 & 4093 & Abu Daud & $\begin{array}{l}\text { Penjelasan tentang keturunan } \\
\text { orang-orang Musyrik }\end{array}$ & في ذراري المشركين \\
\hline 4 & 2064 & Tirmizi & Setiap bayi diatas fitrah & ما جاء كل مولود يولد على الفطرة \\
\hline 5 & 6884 & Ahmad & Musnad Abu Hurairah R.A & مسند أبي هريرة رضي الله عنه \\
\hline 6 & 7387 & Ahmad & Musnad Abu Hurairah RA & مسند أبي هريرة رضي الله عنه \\
\hline 7 & 7463 & Ahmad & Musnad Abu Hurairah RA & مسند أبي هريرة رضي الله عنه \\
\hline 8 & 7540 & Ahmad & Musnad Abu Hurairah RA & مسند أبي هريرة رضي الله عنه \\
\hline 9 & 7574 & Ahmad & Musnad Abu Hurairah RA & مسند أبي هريرة رضي الله عنه \\
\hline 10 & 7906 & Ahmad & Musnad Abu Hurairah RA & مسند أبي هويرة رضي الله عنه \\
\hline 11 & 8739 & Ahmad & Musnad Abu Hurairah RA & مسند أبي هريرة رضي الله عنه \\
\hline 12 & 8949 & Ahmad & Musnad Abu Hurairah RA & مسند أبي هيرة رضي الله عنه \\
\hline
\end{tabular}


GENERASI EMAS

Jurnal Pendidikan Islam Anak Usia Dini

Vol. 01 No. 02, Oktober 2018

\begin{tabular}{|c|c|c|c|c|}
\hline 13 & 9851 & Ahmad & Musnad Abu Hurairah RA & مسند أبي هريرة رضي الله عنه \\
\hline 14 & 14277 & Ahmad & Musnad Jabir bin Abdullah RA & مسند جابر بن عبد الله رضي الله تعلى عنه \\
\hline 15 & 19236 & Ahmad & $\begin{array}{l}\text { Dan dari Hadits Samurah bin } \\
\text { Jundub dari Nabi SAW }\end{array}$ & ومن حديث سمرة بن جندب عن النبي صلى الله عليه وسلم \\
\hline 16 & 507 & Malik & $\begin{array}{l}\text { Aisyah berkata: Rasulullah SAW } \\
\text { bersabda: "Tidaklah seorang } \\
\text { Nabi meninggal..." }\end{array}$ & أن عائشة قالت قال رسول الله ما من نبي يموت حتى يخير \\
\hline
\end{tabular}

Pendidikan anak usia dini adalah tempat bagi anak usia emas untuk mengembangkan fondasi dasar, karena menurut para ahli psikologi, usia dini hanya datang sekali dan tidak dapat diulang lagi, yang sangat menentukan untuk pengembangan kualitas manusia selanjutnya. Benyamin S, Bloom dkk, (dalam Muhyatul Huliyah, 2016) mengemukakan bahwa perkembangan intelektual anak terjadi sangat pesat pada tahun-tahun awal kehidupan anak. Sekitar 50\% variabilitas kecerdasan orang dewasa sudah terjadi ketika anak berusia 4 tahun. Peningkatan 30\% berikutnya terjadi pada usia 8 tahun dan $20 \%$ sisanya pada pertengahan atau akhir dasa warsa kedua (Muhyatul Huliyah, 2016: 61).

Pendidikan Islam merupakan usaha sadar yang dilakukan pendidik dalam rangka mempersiapkan peserta didik untuk meyakini, memahami dan mengamalkan ajaran Islam (Abdul Majid, dkk, 2005: 131). Tujuan Pendidikan Islam adalah terbentuknya peserta didik yang beriman dan bertakwa kepada Allah SWT, berbudi pekerti yang luhur (berakhlak mulia), memiliki pengetahuan tentang ajaran pokok Agama Islam dan mengamalkan dalam kehidupan sehari-hari, serta memiliki pengatahuan yang luas tentang Islam (Depag RI, 2004: 2-3).

Hakikat anak yaitu yang berkaitan tentang perkembangan anak usia dini pernah dikemukakan oleh Bredecamp \& Copple, Brenner, dalam Solehuddin (2001) dan Masitoh sebagai berikut (Masitoh, 214: 14):

1) Anak bersifat unik. Masing-masing anak berbeda satu sama lain. Anak memiliki bawaan, minat, kapabilitas, dan latar belakang kehidupan masingmasing. Dengan demikian, meskipun terdapat pola urutan umum dalam 
GENERASI EMAS

Jurnal Pendidikan Islam Anak Usia Dini

Vol. 01 No. 02, Oktober 2018

perkembangan anak yang dapat

diprediksi, pola perkembangan dan

belajar tetap memiliki perbedaan satu

sama lain. Di samping memiliki

universalitas, menurut Bredecamp

anak juga memiliki keunikan tersendiri seperti dalam gaya belajar, minat, dan latar belakang keluarga.

2) Anak mengekspresikan perilakunya secara relatif spontan. Perilaku yang ditampilkan anak umumnya relatif asli, tidak ditutup-tutupi. Anak akan marah, kalau memang mau marah; dan menangis, kalau memang mau menangis. Kemudian memperlihatkan wajah yang ceria di saat bergembira, dan menampakkan muka murung ketika bersedih hati, tak peduli di mana berada dan dengan siapa (Masitoh, 214: 14).

3) Anak bersifat aktif dan energik. Anak lazimnya senang melakukan berbagai aktivitas. Selama terjaga dari tidur, anak seolah tak pernah berhenti dari beraktivitas, tak pernah lelah, dan tak pernah bosan. Terlebih lagi kalau anak dihadapkan pada kegiatan baru dan menantang. Bagi anak, gerak dan aktivitas merupakan suatu kesenangan.
4) Anak itu egosentris. Dengan sifatnya yang egosentris, ia lebih cenderung melihat dan memahami sesuatu dari sudut pandang dan kepentingannya sendiri. Contohnya, anak menangis kalau menghendaki sesuatu yang tidak dipenuhi oleh orang tuanya atau memaksakan sesuatu terhadap orang lain.

5) Anak memiliki rasa ingin tahu yang kuat dan antusias terhadap banyak hal. Karakteristik perilaku ini terutama menonjol pada anak usia 4-5 tahun. Karena itu sangat lazim jika anak pada usia ini banyak memperhatikan, membicarakan, dan mempertanyakan berbagai hal yang sempat dilihat dan didengarnya, terutama terhadap hal-hal yang baru (Masitoh, 214: 15).

6) Anak bersifat eksploratif dan berjiwa petualang. Terdorong oleh rasa ingin tahu yang kuat terhadap sesuatu hal, anak lazimnya senang menjelajah, mencoba, dan mempelajari hal-hal baru. Misalnya, anak senang membongkar pasang alat-alat mainan yang baru dibelinya.

7) Anak umumnya kaya dengan fantasi. Anak senang dengan hal-hal yang 


\section{GENERASI EMAS}

Jurnal Pendidikan Islam Anak Usia Dini

Vol. 01 No. 02, Oktober 2018

bersifat imajinatif. Berkaitan dengan

karakteristik ini, cerita dapat merupakan suatu kegiatan yang banyak digemari oleh anak.

8) Anak masih mudah frustrasi. Umumnya anak masih mudah menangis atau mudah marah apabila keinginannya tidak terpenuhi.

9) Anak masih kurang pertimbangan dalam bertindak, termasuk yang berkenaan dengan hal-hal yang membahayakan. Hal ini, mengimplikasikan bahwa perlunya lingkungan perkembangan dan belajar yang aman bagi anak sehingga anak dapat terhindar dari kondisi-kondisi yang membahayakan.

10) Anak memiliki daya perhatian yang pendek. Anak lazimnya memiliki daya perhatian yang pendek, kecuali terhadap hal-hal yang secara intrinsik menyenangkan. Anak masih sangat sulit untuk duduk dan memperhatikan sesuatu untuk jangka waktu yang lama.

11) Masa anak merupakan masa belajar yang paling potensial. Masa anak usia dini kadang disebut golden age (usia emas) atau magic years. NAEYC mengkampanyekan masa awal kehidupan ini sebagai masa-masa belajar dengan slogannya Early Years are Learning Years.

12) Anak semakin menunjukkan minat terhadap teman. Seiring dengan perkembangan keterampilan fisiknya, anak usia ini menjadi semakin berminat pada teman-temannya. Ia mulai menunjukkan kemampuan untuk bekerja sama dan berhubungan dengan teman-temannya (Masitoh, 214: 16).

Anak adalah manusia kecil yang memiliki potensi dan harus di kembangkan, memiliki karakteristik tertentu yang khas dan tidak sama dengan orang dewasa, selalu aktif, dinamis, antusias, dan rasa ingin tahu yang besar terhadap apa yang dilihatnya, didengar, dan dirasakannya. Anak usia dini adalah sosok individu yang sedang menjalani suatu proses perkembangan dengan pesat dan fundamental bagi kehidupan selanjutnya (Ningrum, 2018: 13).

Hahekat pendidikan anak usia dini adalah periode pendidikan yang sangat menentukan perkembangan dan arah masa depan seorang anak sebab 


\section{GENERASI EMAS}

Jurnal Pendidikan Islam Anak Usia Dini

Vol. 01 No. 02, Oktober 2018

pendidikan yang dimulai dari usia dini akan membekas dengan baik, jika pada masa perkembangannya dilalui dengan suasana yang baik, harmonis, serasi, dan menyenangkan (Fasli Jalal, 2004). Usia 4-6 tahun (Usia Dini) merupakan masa peka bagi anak, di mana anak mulai sensitif untuk menerima barbagai upaya perkembangan seluruh potensi anak (Yamin Martinis, 2012; Fasli Jalal, 2004).

Masa peka adalah masa terjadinya pematangan fungsi-fungsi fisik dan psikis yang siap merespon stimulasi yang diberikan oleh lingkungan. Di mana pada masa ini merupakan masa untuk meletakkan dasar pertama dalam mengembangkan kemampuan fisik, kognitif, bahasa sosial emosional, konsep diri, disiplin, kemandirian, seni, moral, dan nilai-nilai agama (Depdiknas, 2004). Oleh sebab itu, dibutuhkan suasana belajar, strategi dan stimulus yang sesuai dengan kebutuhan anak agar pertumbuhan dan perkembangan anak tercapai secara optimal (Martinis, 2012).

Berdasarkan Undang-Undang No. 20 Tahun 2003 tentang Sistem Pendidikan Nasional berkaitan tentang
Pendidikan Anak Usia Dini tetulis pada Pasal 28 Ayat 1 yang berbunyi "Pendidikan Anak Usia Dini diselenggarakan bagi anak sejak lahir sampai dengan enam tahun dan bukan merupakan prasyarat untuk mengikuti pendidikan dasar" (Republik Indonesia, 2003; Yuliani Nurani, 2010: 6). Berdasarkan dari hakekat pendidikan anak usia dini bahwa pendidikan anak sejak ia masih kecil itu sangat dibutuhkan sehingga perkembangan anak tidak terhambat dan menyiapkan anak dalam menghadapi kehidupan yang akan dating (Ningrum, 2018: 13).

Pendidikan anak usia dini adalah suatu upaya pembinaan yang di tujukan kepada anak sejak lahir sampai dengan usia enam tahun yang dilakukan melalui pemberian rangsangan pendidikan untuk membantu pertumbuhan dan perkembangan jasmani dan rohani agar anak memiliki kesiapan dalam memasuki pendidikan lebih lanjut (Musbikin, 2011: 35-36). Pendidikan dasar anak usia dini pada dasarnya harus berdasarkan pada nilai-nilai filosofis dan religi yang dipegang oleh lingkungan yang berada di sekitar anak dan agama yang dianutnya. Pendidikan agama menekankan pada 
GENERASI EMAS

Jurnal Pendidikan Islam Anak Usia Dini

Vol. 01 No. 02, Oktober 2018

pemahaman tentang agama serta

bagaimana agama diamalkan dan

diaplikasikan dalam tindakan sarta

perilaku dalam kehidupan sehari-hari.

Penanaman nilai-nilai agama tersebut

disesuaikan dengan tahapan

perkembangan anak serta keunikan yang

dimiliki oleh setiap anak (Nurani, 2010:

9; Ningrum, 2018: 14).

Dasar-dasar pendidikan sosial yang di letakkan agama Islam dalam mendidik anak adalah membiasakan mereka bertingkah laku sesuai dengan etika yang benar dan membentuk akhlak kepribadiannya sejak ia masih usia dini. Jika interaksi sosial dan pelaksanaan etika berpijak pada landasan iman dan taqwa, maka pendidikan sosial akan mencapai tujuannya yang paling tinggi yaitu manusia dengan perangai akhlak dan interaksi yang sangat baik sebagai insan yang shaleh, bijak dan dinamis (Dwi, 2018: 4; Nurani, 2010: 9). Pendidikan ini akan berhasil jika dilakukan semenjak dini (usia 1-6 tahun) (Wibowo, 2012: 25-26).

Menurut Dadan Suryana dalam tulisannya yang berjudul: "Dasar-dasar Pendidikan TK" anak usia dini itu dari usia 0-8 tahun. Beliau berdalil dengan teori sebagai berikut: "Penelitian di bidang neuroscience (ilmu tentang syaraf) menemukan bahwa kecerdasan sangat dipengaruhi oleh banyaknya sel syaraf otak, hubungan antarsel syaraf otak, dan keseimbangan karena otak kanan dan otak kiri. Pada saat lahir sel syaraf otak sudah terbentuk semua yang banyaknya mencapai 100-200 miliar, di mana setiap sel dapat membuat hubungan dengan 20.000 sel syaraf otak lainnya, atau dengan kata lain membentuk kombinasi 100 miliar $\mathrm{x}$ 20.000” (Suryana, 2014: 4).

Penjelasan Dadan Suryana di atas, didukung oleh Bredecamp (1997) sebagaimana dikutip Masitoh dalam "Hakikat Pendidikan dan Pembelajaran di Taman Kanak-kanak" menyatakan bahwa pendidikan anak usia dini mencakup berbagai program yang melayani anak dari lahir sampai dengan delapan tahun yang dirancang untuk meningkatkan perkembangan intelektual, sosial, emosi, bahasa, dan fisik anak (Masitoh, 2014: 6).

Berdasarkan beberapa argument di atas, maka yang dimaksud dengan Pendidikan Anak Usia Dini (PAUD) adalah pendidikan yang diselenggarakan 


\section{GENERASI EMAS}

Jurnal Pendidikan Islam Anak Usia Dini

Vol. 01 No. 02, Oktober 2018

dengan tujuan untuk memfasilitasi

pertumbuhan dan perkembangan anak secara menyeluruh atau menekankan pada pengembangan seluruh aspek perkembangan anak (fitrah) (Nurhadi, 2018).

\section{METODOLOGI PENELITIAN}

Jenis penelitian ini adalah termasuk penelitian kualitatif, karena sifat data yang akan dikumpulkan bercorak kualitatif (Moleong, 2001: 11; Imam Suprayogo and Tobroni, 2002: 9; Bungin Burhan, 2004: 31). Oleh karena itu data penelitian bersifat naturalis dengan memakai logika induktif dan pelaporannya bersifat deskriptif (Nawawi, 2009: 67; Mulyana, 2005: 27). Penelitian ini terfokus pada penelitian kepustakaan (library research) atau studi teks (Putong, 2011: 29; HB Sutopo, 2004: 17). Maka penelitian ini akan lebih memusatkan perhatian pada pengkajianpengkajian terhadap teks, dan termasuk jenis penelitian kualitatif (Hamidi, 2004: 13; Neong Muhajir, 1998: 17). Penelitian kepustakaan dilakukan karena sumbersumber datanya, baik yang utama (primary resources) maupun pendukung (secondary resources) seluruhnya adalah teks (Nazir, 1997: 58; Suprayogo \&

Tobroni, 2002: 21).

\section{PEMBAHASAN}

\section{Asbab al-Nuzul Surah Luqman Ayat 12-19}

Sebelum memaparkan secara detail asbab al-Nuzul ayat, maka penulis akan memaparkan ayat dan terjemahanya sebagai berikut:

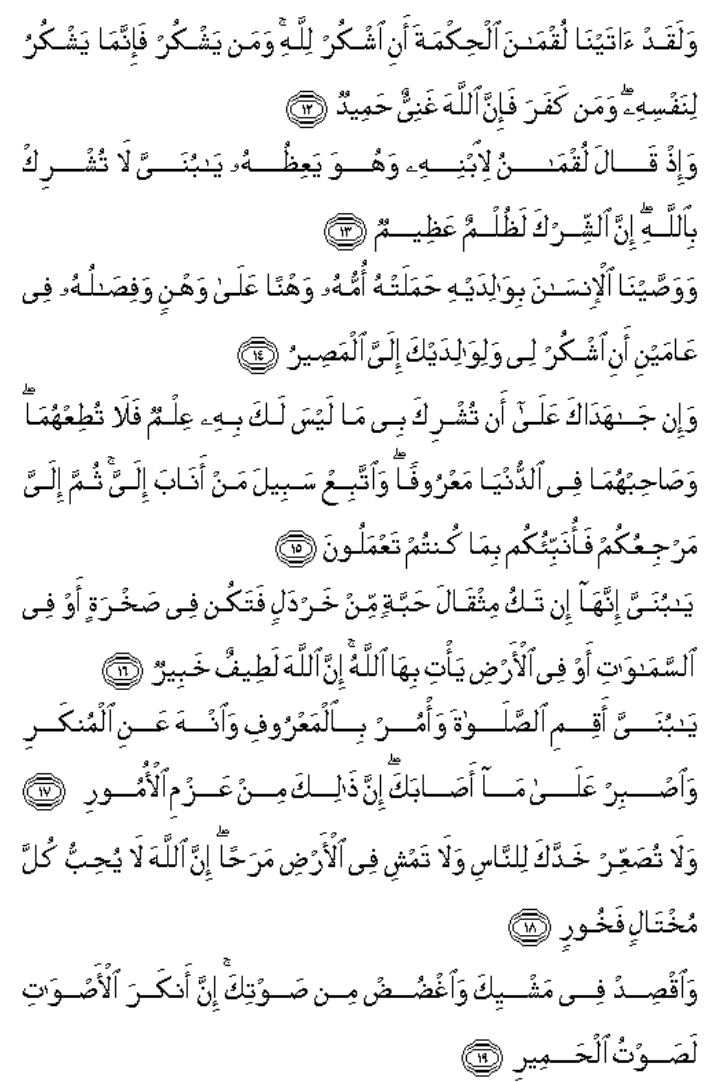

Artinya:

12. Dan Sesungguhnya Telah kami berikan hikmat kepada Luqman, yaitu: "Bersyukurlah kepada Allah. dan barangsiapa yang bersyukur 
GENERASI EMAS

Jurnal Pendidikan Islam Anak Usia Dini

Vol. 01 No. 02, Oktober 2018

(kepada Allah), Maka

Sesungguhnya ia bersyukur untuk dirinya sendiri; dan barangsiapa yang tidak bersyukur, Maka Sesungguhnya Allah Maha Kaya lagi Maha Terpuji".

13. Dan (Ingatlah) ketika Luqman Berkata kepada anaknya, di waktu ia memberi pelajaran kepadanya: "Hai anakku, janganlah kamu mempersekutukan Allah, Sesungguhnya mempersekutukan (Allah) adalah benar-benar kezaliman yang besar".

14. Dan kami perintahkan kepada manusia (berbuat baik) kepada dua orang ibu- bapanya; ibunya Telah mengandungnya dalam keadaan lemah yang bertambah- tambah, dan menyapihnya dalam dua tahun (maksudnya: Selambat-lambat waktu menyapih ialah setelah anak berumur dua tahun). bersyukurlah kepadaku dan kepada dua orang ibu bapakmu, Hanya kepada-Kulah kembalimu.

15. Dan jika keduanya memaksamu untuk mempersekutukan dengan Aku sesuatu yang tidak ada pengetahuanmu tentang itu, Maka janganlah kamu mengikuti keduanya, dan pergaulilah keduanya di dunia dengan baik, dan ikutilah jalan orang yang kembali kepada-Ku, Kemudian Hanya kepada-Kulah kembalimu, Maka Kuberitakan kepadamu apa yang Telah kamu kerjakan.

16. (Luqman berkata): "Hai anakku, Sesungguhnya jika ada (sesuatu perbuatan) seberat biji SAWi, dan berada dalam batu atau di langit atau di dalam bumi, niscaya Allah akan mendatangkannya (membalasinya). Sesungguhnya Allah Maha Halus (yang dimaksud dengan Allah Maha Halus ialah ilmu Allah itu meliputi segala sesuatu bagaimana kecilnya) lagi Maha Mengetahui. 17. Hai anakku, Dirikanlah shalat dan suruhlah (manusia) mengerjakan yang baik dan cegahlah (mereka) dari perbuatan yang mungkar dan Bersabarlah terhadap apa yang menimpa kamu. Sesungguhnya yang demikian itu termasuk hal-hal yang diwajibkan (oleh Allah).

18. Dan janganlah kamu memalingkan mukamu dari manusia (karena sombong) dan janganlah kamu berjalan di muka bumi dengan angkuh. Sesungguhnya Allah tidak menyukai orang-orang yang sombong lagi membanggakan diri. 19. Dan sederhanalah kamu dalam berjalan (maksudnya: ketika kamu berjalan, janganlah terlampau cepat dan jangan pula terlalu lambat) dan lunakkanlah suaramu. Sesungguhnya seburuk-buruk suara ialah suara keledai.

Adapun asbab al-Nuzul (sebab turun ayat) di sini dimaksudkan sebabsebab yang secara khusus berkaitan dengan turunnya ayat-ayat tertentu. Sedangkan menurut Subhi al-Salih, asbab an-Nuzul adalah sesuatu yang dengan sebabnya turun ayat atau beberapa ayat yang mengandung sebab itu, atau memberi jawaban terhadap 


\section{GENERASI EMAS}

Jurnal Pendidikan Islam Anak Usia Dini

Vol. 01 No. 02, Oktober 2018

sebab itu atau menerangkan hukumnya

Rasulullah SAW lalu membacakan al-

pada masa terjadinya sebab tersebut

Qur'an kepadanya dan mengajaknya

(Ahmad Musthafa, 1992: 152).

Penulis secara transparan sesuai dengan refrensi yang dilacak, menyatakan bahwa, asbab al-Nuzul Surat Luqman Ayat 12-19 tidak penulis temukan secara menyeluruh, namun hanya menemukan $a s b a b$ al-Nuzul ayat 13, 14, 15 dan 18, keterangannya sebagai berikut:

1) Asbab al-Nuzul ayat 13 dalam tafsir AlMisbah, diriwayatkan bahwa Suwayd ibn ash-Shamit suatu ketika datang ke mekah. Ia adalah seorang yang cukup terhormat di kalangan masyarakatnya. Lalu Rasulullah SAW mengajaknya untuk memeluk agama Islam. Suwayd berkata kepada Rasulullah SAW, "Mungkin apa yang ada padamu itu sama dengan yang ada padaku." Rasulullah SAW berkata: "Apa yang ada padamu?" Ia menjawab, "Kumpulan hikmah Lukman." Kemudian Rasulullah SAW berkata: "Sungguh perkataan yang amat baik! Tetapi apa yang ada padaku lebih baik dari itu. Itulah al-Qur'an yang diturunkan Allah SWT kepadaku untuk menjadi petunjuk dan cahaya." memeluk Islam (M. Quraish Shihab, 2010: 125). Jika dilihat dalam shahih kutub al-Tis'ah, maka akan ditemukan asbab al-Nuzul ayat 13, yaitu: "Dari Abdullah berkata: ketika turun ayat: "Orang-orang beriman dan tidak mencampur adukkan iman mereka dengan kezhaliman" para sahabat Rasulullah SAW bertanya: "Siapakah diantara kami yang tidak berbuat zhalim? Maka Allah 'azza wajalla menurunkan

(firman-Nya):

"Sesungguhnya kesyirikan adalah kezhaliman yang besar". (QS. Luqman: 13) (HR. Bukhari No. 31). Dilain riwayat dari 'Abdullah R.a berkata; "Ketika turun QS al-An'am ayat 82 yang artinya ("Orang-orang beriman dan tidak mencampur iman mereka dengan kezhaliman..."), kami berkata; "Wahai Rasulullah SAW, siapakah diantara kami orang yang tidak menzhalimi dirinya?". Maka Beliau bersabda: "Bukan seperti yang kalian katakan. Maksud ayat "tidak mencampurkan iman mereka dengan kezhaliman" adalah dengan kesyirikan. Tidakkah kalian mendengar ucapan 
GENERASI EMAS

Jurnal Pendidikan Islam Anak Usia Dini

Vol. 01 No. 02, Oktober 2018

Luqman kepada anaknya? (Wahai anakku, janganlah kamu menyekutukan Allah karena menyekutukan Allah merupakan kezhaliman yang besar") (Qs. Luqman: 13) (HR Bukhari No. 3110, 3174, 3175, 4403, 4405, 6407, 6424; HR. Muslim No. 174; HR. Tirmizi No. 2993; HR. Ahmad No. 3826, 4019) (Satu Warna, 2012: 412). Menurut Sayid Qutb bahwa ayat 13 yang menjelaskan tentang tauhid, inilah hakikat yang ditawarkan oleh nabi Muhammad SAW kepada kaumnya. Namun, mereka menentangnya dalam perkara itu, dan meragukan maksud baiknya dibalik tawarannya. Mereka takut dan khawatir bahwa dibalik tawaran itu terdapat ambisi Muhammad SAW untuk merampas kekuasaan dan kepemimpinan atas mereka.

2) Asbab al-Nuzul ayat 14 dan 15 penulis menemukan riwayat bahwa ayat ini menggambarkan nuansa pengorbanan yang agung dan dahsyat. Seorang ibu yang dengan tabiatnya harus menanggung beban yang lebih berat dan lebih kompleks. Namun, luar biasa, ia tetap menanggungnya dengan senang hati dan cinta yang lebih dalam, lembut, dan halus. Diriwayatkan oleh Hafidz
Abu Bakar al-Bazzar dalam musnadnya dengan sanadnya dari Buraid dari ayahnya bahwa seseorang sedang berada dalam barisan tawaf menggendong ibunya untuk membawanya bertawaf. Kemudian dia bertanya kepada Nabi Muhammad SAW: "Apakah aku telah menunaikan haknya?" Rasulullah SAW menjawab: "Tidak, walaupun satu tarikan nafas." (Sayyid Quthb. 2014: 174). Diriwayatkan bahwa ayat 15 ini diturunkan berhubungan dengan Sa'ad bin Abi Waqqas, ia berkata, "Tatkala aku masuk Islam, ibuku bersumpah bahwa beliau tidak akan makan dan minum sebelum aku meninggalkan agama Islam itu. Untuk itu pada hari pertama aku mohon agar beliau mau makan dan minum, tetapi beliau menolaknya dan tetap bertahan pada pendiriannya. Pada hari kedua, aku juga mohon agar beliau mau makan dan minum, tetapi beliau masih tetap pada pendiriannya. Pada hari ketiga, aku mohon kepada beliau agar mau makan dan minum, tetapi tetap menolaknya. Oleh karena itu, aku berkata kepadanya, Demi Allah, seandainya ibu mempunyai seratus jiwa dan keluar satu 
GENERASI EMAS

Jurnal Pendidikan Islam Anak Usia Dini

Vol. 01 No. 02, Oktober 2018

persatu di hadapan saya sampai ibu

mati, aku tidak akan meninggalkan agama yang aku peluk ini. Setelah

ibuku melihat keyakinan dan kekuatan

pendirianku, maka beliaupun mau

makan (Muhammad, et., all, 2010: $553)$.

3) Asbab al-Nuzul ayat 18 penulis temukan dalam kutub al-Tis'ah, riwayat Ahmad: "seseorang yang mendapatkan tetangganya selalu mencaci dan mengganggunya, sedang ia tetap bersabar dan berharap Allah akan menghentikannya dengan kematian atau semasa hidupnya. Dan seseorang yang melakukan perjalanan dengan sekelompok kaum hingga terasa lelah dan kantuk mereka, tetapi ia bangun di akhir malam, ia bangun dan shalat." Mutharrif berkata, "Lalu siapa tiga kelompok yang Allah murka padanya?" Abu Dzar menjawab, "Orang-orang yang sombong lagi berbangga diri, dan engkau dapatkan dalam Kitabullah; (QS. Luqman: 18)" dan (HR. Ahmad No. 20550).

\section{Multiple Intelligences Anak Usia Dini dalam Surah Luqman Ayat 12-19}

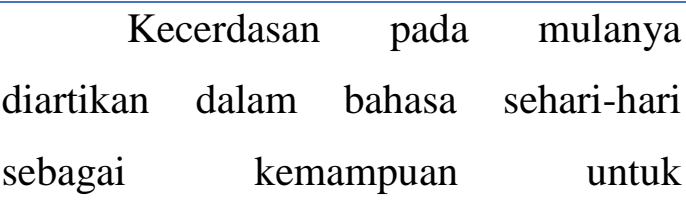

menyelesaikan persoalan-persoalan praktis, dan terdapat persepsi bahwa kemampuan untuk belajar berasal dari kapasitas kognitif (Chatib, 2010: 89). Selanjutnya, makna ini harus diperluas dan lebih fundamental karena pada dasarnya kecerdasan dan aspek kognitif tak terpisahkan dari aktifitas pikiran atau kesadaran manusia secara utuh dalam hubungannya dengan aspek-aspek diri manusia seutuhnya serta interaksinya dengan lingkungannya (Suarca, dkk, 2005: 85).

\section{Multiple Intelligences yang} dalam bahasa Indonesia diterjemahkan sebagai kecerdasan majemuk atau kecerdasan ganda merupakan salah satu teori kecerdasan yang memperoleh banyak pengakuan akhir-akhir ini (Jasmine, 2007: 13). Teori ini dicetuskan oleh Howard Gardner, psikolog dari Harvard. Mula-mula Gardner menemukan tujuh jenis kecerdasan kemudian mengembangkannya menjadi delapan, dan membahas kemungkinan kecerdasan yang ke Sembilan (Musfiroh, t.th: 1). 
GENERASI EMAS

Jurnal Pendidikan Islam Anak Usia Dini

Vol. 01 No. 02, Oktober 2018

Di dunia pendidikan, teori multiple intelligences mulai diterima karena dianggap lebih melayani semua kecerdasan yang dimiliki anak. Konsep Multipel Intelegensi menjadikan pendidik lebih arif melihat perbedaan, dan menjadikan anak merasa lebih diterima dan dilayani (May Lwin, dkk, 2005: 5). Konsep ini "menghapus" mitos anak cerdas dan tidak cerdas, karena menurut konsep ini, semua anak hakikatnya cerdas. Hanya saja konsep cerdas itu perlu diredefinisi dengan landasan baru. (Musfiroh, t.th: 1; Suharsono, 2004: 47).

Berbagai ilmu dari Gardner yang telah menemukan teori kecerdasan majemuk atau multiple intelligence bahwa ada banyak kecerdasan yang dimiliki setiap orang. Teori ini juga menekankan pentingnya "model" atau teladan yang sudah berhasil mengembangkan salah satu kecerdasan hingga puncak (Djaali, 2007: 73).

Islam disamping yakin akan adanya banyak segi manusia yaitu jasmani, akal dan rohaninya dengan berbagi kebutuhan daya setiap segi itu, meyakini pula kesatuan dan keterpaduan wujud manusia tersebut dan tidak mungkin dipisah-pisahkan satu dengan yang lain. Fitrah manusia berjalan menurut garis yang telah diciptkan Allah SWT. Dengan demikian jasmani, akal dan roh yang ada dalam diri manusia tidak mungkin dapat dipisah-pisahkan. Roh, akal dan tubuh, ketiganya membentuk satu wujud yang utuh, yang disebut manusia, semuanya berinteraksi secara utuh. Islam mengikuti aliran fitrah yang ada dan meyakini bahwa ada saling keterikatan antra unsur-unsur tersebut (Baihaqi, 2014: 9).

\section{Keterkaitan antara teori Multipel} Intelegensi dan konsep fitrah ini begitu penting karena beberapa hal, diantaranya adalah: (1) Teori Multipel Intelegensi berusaha mengungkapkan potensi yang ada dalam diri manusia, sehingga proses pembelajaran idealnya harus sesuai bakat yang dimilikinya, (2) Konsep Fitrah menyebutkan bahwa manusia sebagai ciptaan Allah dilahirkan dalam keadaan suci dan membawa potensi-potensi. Hal ini sejalan dengan teori yang awal. (3) Dengan mengkolaborasikan teori dan konsep di atas, maka akan tercipta pandangan yang benar terhadap peserta didik yang sejatinya adalah jalan untuk 
GENERASI EMAS

Jurnal Pendidikan Islam Anak Usia Dini

Vol. 01 No. 02, Oktober 2018

menjadikan pendidikan lebih maju

berujung sukses (Putri. 2016: 91;

(Baihaqi, 2014: 10).

Goleman. D. 2000: 13). Sebuah

Menurut penulis konsep kemampuan untuk "mendengarkan" kecerdasan majemuk atau Multipel bisikan emosi dan menjadikannya Intelegensi sama dengan fitrah manusia. Artinya, kecerdasan yang sesuai dengan fitrah manusia lahir di dunia. Namun manusia dan lingkungan sekitarnya yang harus mengembangkanya. Teori kecerdasan Multipel Intelegensi dalam teori Islam sering disebut dengan kecerdasan spritual, emosional dan intelektual.

Konsep kecerdasan spiritual merupakan salah satu kecerdasan yang menjadi puncak kecerdasan atau menjadi kecerdasan tertinggi (Nhera Tomi, 2015). Artinya, kecerdasan spiritual lebih tinggi daripada kecerdasan emosional dan kecerdasan intelektual. Sering disebut dengan kecerdasan afektif.

Konsep kecerdasan emosional menurut Daniel Goleman dengan hasil riset terbaru itu cukup lebih memberikan kesimpulan mengapa orang ber-IQ tinggi gagal dan orang ber-IQ rendah justru menjadi sukses, dikarenakan ber-IQ tinggi tidak punya nyali, akhirnya gagal, ber-IQ rendah tapi nyalinya tinggI sebagai sumber informasi maha penting untuk memahami diri sendiri dan orang lain demi mencapai sebuah tujuan (Agustian, Ari Ginanjar. 2003: 61-62; Stheppen Robbins P., 2001: 335). Sering disebut dengan keceerdasan psikomotor.

Konsep kecerdasan intelektual sering disebut sebagai kecerdasan yang mengacu terhadap kemampuan kognitif seseorang, yaitu kemampuan berpikir yang tinggi dalam usaha meningkatkan kemampuan yang dimiliki (Anwar, 2005: 5). Kemampuan untuk bekerja secara abstrak, baik menggunakan ideide, simbol, hubungan logis, maupun konsep-konsep teoritis (Putri, 2016: 90). Sering disebut dengan kecerdasan kognitif.

Menurut penulis kecerdasan Multipel Intelegensi dan kecerdasan spritual, emosional dan intelektual dalam kajian filsafat pendidikan Islam disebut dengan kecerdasan Imaniyah, Amaliyah dan Fikriyah. Istilah ini, penulis simpulkan dari sejarah Islam tentang kecerdasan para hamba pembawa syariat 


\section{GENERASI EMAS}

Jurnal Pendidikan Islam Anak Usia Dini

Vol. 01 No. 02, Oktober 2018

(para Nabi dan Rasul SAW), kecerdasan

para sahabat Nabi dan Rasul SAW dan

kecerdasan para ulama (mujtahid fiqih).

\section{Kecerdasan Imaniyah (Spiritual)}

Kecerdasan imaniyah, yaitu kecerdasannya para Nabi dan Rasul, terutama Nabi Muhammad SAW, beliau seorang yang ummi (tidak pandai baca tulis), namun kecerdasannya melebihi manusia yang ada (dari awal penciptaan sampai akhir zaman), karena para Nabi mempunyai sifat yang wajib, yaitu siddik, amanah, tabligh, fathanah. Kecerdasan ini hanya bermodalkan iman dan keyakinan kepada yang memberikan ilmu dan kecerdasan (Allah SWT), yang maha wujud dan qidam serta maha alim (mengetahui).

\section{Kecerdasan Amaliyah (Emosional)}

Kecerdasan amaliyah adalah kecerdasan para sahabat Nabi SAW, yatiu kecerdasan yang diawali dengan amal shaleh bukti dari keimanan. Abu Bakar orang yang paling alim diantara para sahabat dan sahabat Nabi yang paling tua (senior), orang pertama kali masuk Islam dari kalangan lak-laki (orang tua). Kecerdasan amaliyah beliau dibuktikan dengan keyakinan akan kebenaran peristiwa isra mi'raj, sehingga beliau mendapat gelar al-Siddik (yang membenarkan). Keyakinan itu diperoleh dengan hikmah dari amaliyahnya (amal shalehnya). Demikian halnya Umar bin Khathab, dikenal orang yang sangat ditakuti jin dan setan dikarenakan amaliyahnya. Berkat amaliyahnya (amal shalehnya), Umar disebut dengan singa padang pasir. Dalam sebuah riwayat disebutkan, kalau ada Nabi setelah Nabi Muhammad SAW, maka Umarlah yang paling pantas menjadi Nabi dikarenakan kecerdasanya. Juga dengan kecerdasan amaliyahnya beliau penggagas pertama untuk menulis dan mengumpulkan al-Qur'an. Juga Usman bin Affan terkenal dengan ketawadu'annya (rendah hati dan pemalu). Berkat amaliyahnya beliau memiliki kecerdasan yang sangat luar biasa, sehingga diantara sahabat yang dapat menaklukkan Nabi SAW dengan mempersuntung dua putri Nabi SAW adalah Usman, dengannya digelari ( $z h u$ Nur'ain), yaitu sang pemilik dua mata. Sedangkan Ali bin Abi Thalib, berkah amaliyahnya beliau memiliki kecerdasan yang luar biasa, sehingga beliau dijuluki dengan babul ilmu, sebagaimana dalam 


\section{GENERASI EMAS}

Jurnal Pendidikan Islam Anak Usia Dini

Vol. 01 No. 02, Oktober 2018

riawayat disebutkan bahwa Nabi SAW

gudang ilmu dan Ali adalah pintunya.

\section{Kecerdasan Fikriyah (Intelektual)}

Sedangkan kecerdasan Fikriyah adalah kecerdasan yang dimiliki para ulama mujtahid, terutama mujtahid mutlak, yaitu imam Hanafi, Maliki, Syafi'i dan Hambali. Dengan kecerdasan fikriyahnya mereka mampu membuat teori istinbath hukum Islam, yang dikenal dengan teori usul fiqih. Sehingga tidak heran dengan kecerdasan fikriyahnya, para mujtahid mutlak tersebut berijtihad tentang suatu hukum, terkadang berbeda dalil dan berbeda hasil ijtihad, kendatipun subtansinya sama. Hal ini terjadi dikarenakan kecerdasan fikriyahnya dalam merumuskan usul fiqih masing-masing mereka. Bahkan sampai sekarang, jika tanpa kecerdasan fikriyah para ulama mujtahid tersebut, kemungkinan umat saat ini akan jumud dan terjerumus dalam kesulitan.

Melalui tiga kategori kecerdasan di atas, lalu bagaimana jika diaplikasikan dalam dunia pendidikan dikaitkan dengan ayat-ayat tarbawi, semisal surah Luqman Ayat 12-19, maka dapat dilihat klasifikasinya sebagai berikut:

Tabel 2 Aplikasi Surah Luqman Ayat 12-19 dalam Dunia Pendidikan

\begin{tabular}{|c|c|c|c|c|c|c|}
\hline No & $\begin{array}{c}\text { Mata Pelajaran } \\
\text { dalam ayat } 12-19\end{array}$ & Kecerdasan & Waktu & Anak & Kelas & ljazah \\
\hline 1 & Iman & Imaniyah & $0-9$ bulan 10 hari & Kandungan & $\mathrm{K}$ & Didengar \\
\hline 2 & Aqidah & Imaniyah & 0-1 tahun kelahiran & Bayi & $\mathrm{K}$ & Dihapal \\
\hline 3 & Tauhid & Imaniyah & 1-3 tahun kelahiran & Balita & $\mathrm{K}$ & Dimengerti \\
\hline 4 & Syukur kepada Allah SWT & Amaliyah & 3-5 tahun kelahiran & Anak-Anak & $\mathrm{K}$ & Dipaham \\
\hline 5 & Shalat & Amaliyah & 5- 7 tahun kelahiran & Mumayyiz & $\mathrm{S} / \mathrm{K}$ & Diamal \\
\hline 6 & $\begin{array}{l}\text { Berbakti Kepada Orang } \\
\text { Tua }\end{array}$ & Amaliyah & 7-8 tahun kelahiran & Mumayyiz & $\mathrm{S} / \mathrm{K}$ & Soleh/ah \\
\hline 7 & Bertanggung Jawab & Intelektual & 7-8 tahun kelahiran & Mumayyiz & $\mathrm{S} / \mathrm{K}$ & Jujur \\
\hline 8 & Toleransi & Intelektual & 7-8 tahun kelahiran & Mumayyiz & $\mathrm{S} / \mathrm{K}$ & Lapang \\
\hline 9 & Sabar & Intelektual & 7-8 tahun kelahiran & Mumayyiz & $\mathrm{S} / \mathrm{K}$ & Rela \\
\hline 10 & Tawaduk & Intelektual & 7-8 tahun kelahiran & Mumayyiz & $\mathrm{S} / \mathrm{K}$ & Tunduk \\
\hline 11 & Amar Ma'ruf & Intelektual & 7-8 tahun kelahiran & Mumayyiz & $\mathrm{S} / \mathrm{K}$ & Dakwah \\
\hline 12 & Nahi Mungkar & Intelektual & 7-8 tahun kelahiran & Mumayyiz & $\mathrm{S} / \mathrm{K}$ & Dakwah \\
\hline 13 & Ta'at Ibadah & Intelektual & 7-8 tahun kelahiran & Mumayyiz & $\mathrm{S} / \mathrm{K}$ & Surga \\
\hline \multicolumn{7}{|c|}{ Ket: $S=$ sekolah. $\quad K=$ keluarga. } \\
\hline
\end{tabular}




\section{GENERASI EMAS}

Jurnal Pendidikan Islam Anak Usia Dini

Vol. 01 No. 02, Oktober 2018

Tabel 3 Aplikasi Langsung Surah Luqman Ayat 12-19

\begin{tabular}{|c|c|c|c|c|}
\hline No & $\begin{array}{c}\text { Kecerdasan } \\
\text { Imaniyah }\end{array}$ & $\begin{array}{c}\text { Kecerdasan } \\
\text { Amaliyah }\end{array}$ & Kecerdasan Fikriyah & Nilai-Nilai \\
\hline 1 & $\begin{array}{l}\text { Bersyukurlah kepada Allah. } \\
\text { Dan barang siapa yang } \\
\text { bersyukur (kepada Allah), } \\
\text { maka sesungguhnya ia } \\
\text { bersyukur untuk dirinya } \\
\text { sendiri; dan barang siapa } \\
\text { yang tidak bersyukur, maka } \\
\text { sesungguhnya Allah Maha } \\
\text { Kaya lagi Maha Terpuji. }\end{array}$ & $\begin{array}{l}\text { Dirikanlah salat dan } \\
\text { suruhlah (manusia) } \\
\text { mengerjakan yang } \\
\text { baik dan cegahlah } \\
\text { (mereka) dari } \\
\text { perbuatan yang } \\
\text { mungkar }\end{array}$ & $\begin{array}{l}\text { Dan (ingatlah) ketika Lukman } \\
\text { berkata kepada anaknya, di } \\
\text { waktu ia memberi pelajaran } \\
\text { kepadanya: }\end{array}$ & $\begin{array}{l}\text { Afektif (SQ) } \\
\text { Psikomotor } \\
\text { (EQ) } \\
\text { Kognitif (IQ) }\end{array}$ \\
\hline 2 & $\begin{array}{l}\text { "Hai anakku, janganlah kamu } \\
\text { mempersekutukan (Allah) } \\
\text { sesungguhnya } \\
\text { mempersekutukan (Allah) } \\
\text { adalah benar-benar kelaliman } \\
\text { yang besar". }\end{array}$ & $\begin{array}{l}\text { Sesungguhnya yang } \\
\text { demikian itu termasuk } \\
\text { hal-hal yang } \\
\text { diwaibkan (oleh } \\
\text { Allah). }\end{array}$ & $\begin{array}{l}\text { Dan Kami perintahkan kepada } \\
\text { manusia (berbuat baik) kepada } \\
\text { dua orang ibu-bapaknya; ibunya } \\
\text { telah mengandungnya dalam } \\
\text { keadaan lemah yang bertambah- } \\
\text { tambah, dan menyapihnya dalam } \\
\text { dua tahun. Bersyukurlah kepada- } \\
\text { Ku dan kepada dua orang ibu } \\
\text { bapakmu }\end{array}$ & $\begin{array}{l}\text { Afektif (SQ) } \\
\text { Psikomotor } \\
\text { (EQ) } \\
\text { Kognitif (IQ) }\end{array}$ \\
\hline 3 & $\begin{array}{l}\text { Dan jika keduanya } \\
\text { memaksamu untuk } \\
\text { mempersekutukan dengan } \\
\text { Aku sesuatu yang tidak ada } \\
\text { pengetahuanmu tentang itu, } \\
\text { maka janganlah kamu } \\
\text { mengikuti keduanya. }\end{array}$ & & $\begin{array}{l}\text { Dan pergaulilah keduanya di } \\
\text { dunia dengan baik, dan ikutilah } \\
\text { jalan orang yang kembali kepada- } \\
\text { Ku }\end{array}$ & $\begin{array}{l}\text { Afektif (SQ) } \\
\text { Kognitif (IQ) }\end{array}$ \\
\hline 4 & $\begin{array}{l}\text { hanya kepada-Kulah } \\
\text { kembalimu. }\end{array}$ & & $\begin{array}{l}\text { Dan bersabarlah terhadap apa } \\
\text { yang menimpa kamu }\end{array}$ & $\begin{array}{l}\text { Afektif (SQ) } \\
\text { Kognitif (IQ) }\end{array}$ \\
\hline 5 & $\begin{array}{l}\text { Kemudian hanya kepada- } \\
\text { Kulah kembalimu, maka Ku- } \\
\text { beritakan kepadamu apa yang } \\
\text { telah kamu kerjakan. }\end{array}$ & & $\begin{array}{l}\text { Dan janganlah kamu } \\
\text { memalingkan mukamu dari } \\
\text { manusia (karena sombong) dan } \\
\text { janganlah kamu berjalan di muka } \\
\text { bumi dengan angkuh. } \\
\text { Sesungguhnya Allah tidak } \\
\text { menyukai orang-orang yang } \\
\text { sombong lagi membanggakan } \\
\text { diri. }\end{array}$ & $\begin{array}{l}\text { Afektif (SQ) } \\
\text { Kognitif (IQ) }\end{array}$ \\
\hline 6 & $\begin{array}{l}\text { "Hai anakku, sesungguhnya } \\
\text { jika ada (sesuatu perbuatan) } \\
\text { seberat biji sawi, dan berada } \\
\text { dalam batu atau di langit atau } \\
\text { di dalam bumi, niscaya Allah } \\
\text { akan mendatangkannya } \\
\text { (membalasinya). } \\
\text { Sesungguhnya Allah Maha } \\
\text { Halus lagi Maha Mengetahui. }\end{array}$ & & $\begin{array}{l}\text { Dan sederhanalah kamu dalam } \\
\text { berjalan dan lunakkanlah } \\
\text { suaramu. Sesungguhnya } \\
\text { seburuk-buruk suara ialah suara } \\
\text { keledai. }\end{array}$ & $\begin{array}{l}\text { Afektif (SQ) } \\
\text { Kognitif (IQ) }\end{array}$ \\
\hline
\end{tabular}




\section{GENERASI EMAS}

Jurnal Pendidikan Islam Anak Usia Dini

Vol. 01 No. 02, Oktober 2018

\section{PENUTUP}

Kecerdasan Multipel Intelegensi dan kecerdasan spritual, emosional dan intelektual dalam kajian filsafat pendidikan Islam disebut dengan kecerdasan Imaniyah, Amaliyah dan Fikriyah. Istilah ini penulis simpulkan dari sejarah Islam tentang kecerdasan para hamba pembawa syariat (para Nabi dan Rasul SAW), kecerdasan para sahabat Nabi dan Rasul SAW dan keserdasan para ulama (mujtahid fiqih). Dalam surah Luqman ayat 12-19, maka mengandung mata pelajaran iman, aqidah, tauhid adalah kecerdasan imaniyah. syukur kepada Allah SWT, shalat, berbakti kepada orang tua adalah kecerdasan amaliyah. bertanggung jawab, toleransi, sabar, tawaduk, amar ma'ruf, nahi mungkar, ta'at ibadah adalah kecerdasan intelektual. Sesuai dengan fitrahnya, maka manusia sekalipun anak usia dini wajib mendpatkan pengajaran tentang Multipel Intelegensi secara konprehensif, karena anak usia dini masih fitrah, karenanya orang tua sebagai guru pertama harus mengungkapkan kecerdasan tersebut pada anaknya. Agar terbangun dan sadar akan potensi insan kamil pada dirinya sebagai hamba Alllah SWT. Karena anak usia dini adalah usia keemasan bagi anak untuk kebangkitan jiwa kesuksesan dunia akhirat.

\section{DAFTAR PUSTAKA}

Abdullah Malik ibn Anas ibn Malik ibn Abi Amir ibn Amr ibn al-Haris ibn Gaiman ibn Husail ibn Amr ibn al-Haris alAsbahi al-Madani. t.th. Al-Mua'tha' Imam Malik. Beirut: Dar Fikri.

Abdurrahman ibn 'Abdirahman ibn al-Fadhl ibn Bahram ibn 'Abdis Shamad. t.th. AlSunan Al-Darimi. Kairo Mesir: Maktabah alamiyah.

Abu 'Abdillah Muhammad bin Yazid bin 'Abdillah bin Majah al-Qazwini. t.th. AlSunan Ibnu Majah. Mesir: Maktabah alSunnah.

Abu 'Abdirrahman Ahmad bin Su'aib bin Ali bin Bahr bin Sinan bin Dinar an-Nasai al-Kurasani. t.th. Al-Sunan al-Nasa'i. Cairo: Dar Ilmi.

$\mathrm{Abu}$ 'Isa muhammad bin 'Isa bin Surrah alTurmudzi Ibn Musa Ibn Adh-Dhahak Al-Sulami Al-Bughi Al-Tirmidzi. t.th. Al-Sunan Al-Tirmizi. Lebanon: Dar alHadis.

Abu Abdullah Muhammad bin Ismail AlBukhari bin Ibrahim bin Al-Mughirah bin Bardizbah, (t.th), Imam al-Bukhari, Sahih Bukhari. Bairut: Darul Ibnu Katsir al-Yammah.

Abu Ja'far Muhammad bin Jarir Ath-Thabari. 2008. Jami' Al-Bayan an-Ta'wil Ayi AlQur'an, penerjemah: Abdul Somad, Yusuf Hamdani, dkk, Jakarta: Pustaka Azzam

Abul Husain Muslim bin al-Hajjaj alNaisaburi, Imam Muslim. t.th. Shahih Muslim. Beirut: Dar Ibnu Katsir.

Agustian, Ari Ginanjar. 2003. ESQ Power: Sebuah Inner Journey Melalui AlIhsan. Jakarta: Penerbit Arga. 


\section{GENERASI EMAS}

Jurnal Pendidikan Islam Anak Usia Dini

Vol. 01 No. 02, Oktober 2018

Al-maraghi, Ahmad Musthafa. 1992. Tafsir al-Maraghi, Terj. Bahrun Abubakar. Semarang : Toha Putra. Juz XXI.

Anwar. 2005. Pengantar Psikol ogi Intelegensi. Yogyakarta : Pustaka belajar.

Baihaqi. 2014. Relevansi Teori Multipel Intelegensi dengan Konsep Fitrah dalam Pendidikan Islam. Pendidikan Agama Islam (PAI) Fakultas Ilmu Tarbiyah dan Keguruan Institut Agama Islam Negeri (IAIN) Walisongo Semarang.

Bredecamp. S. \& Cople, C. 1997. Developmentally Appropriate Practice. USA: National Association for the Young Children.

Burhan, Bungin. 2004. Metodologi Penelitian Kualitatif. Jakarta: Raja Grafindo Persada.

Chatib, Munif. 2010. Sekolahnya Manusia, Sekolah Berbasis Multiple Intelligence di Indonesia; cet ke-1. Bandung: Kaifa.

Darajat, Zaskiyah. 2009. Ilmu Pendidikan Islam. Jakarta: Bumi Aksara Depag-RI.

Departemen Agama RI. 2004. Pedoman Pendidikan Agama Islam di Sekalah Umum. Jakarta: Depag RI.

Departemen Agama RI. 2015. Al-Qur'an dan Terjemahanya. Semarang: Toha Putra.

Departemen Pendidikan Nasional. (2002). Kamus Besar Bahasa Indonesia. Jakarta: Balai Pustaka.

Depdiknas. 2004. Materi Pelatihan Terintergrasi Bahasa dan Sastra Indonesia. Jakarta: Dirjen Pendidikan Dasar dan Menengah Depdiknas.

Djaali. 2007. Psikologi Pendidikan; cet ke-2. Jakarta: Bumi Aksara.
Ghazali, Imam, Diterjemahkan oleh Ismail Yakub. 2003. Ihya' Ulumiddin Imam Ghazali. Jakarta: Pustaka Nasional.

Goleman, D. 2000. Kecerdasan Emosi: Mengapa EI Lebih Tinggi daripada IQ. Alih Bahasa: T. Hermay. Jakarta: PT. Gramedia PustakaUtama.

Hamidi. 2004. Metode penelitian kualitatif. Malang: Universitas Muhammadiyah Malang.

Hasan, Maimun. 2011. PAUD Pendidikan Anak Usia Dini. Jogjakarta: Diva Press.

Hasbullah. 2010. Dasar-Dasar Ilmu Pendidikan. Jakarta: Raja Grafindo Persada.

HB Sutopo. 2004. Pengantar Penelitian Kualitatif. Surakarta: Universitas Sebelas Maret Press.

Hidayat, Bahril; Putra, Ary Antony; Harahap. Musaddad. 2018. Pendidikan Anak Usia Dini Menurut Psikologi Islami. Generasi Emas: Jurnal Pendidikan Islam Anak Usia Dini Volume 1 No. 1. Pekanbaru: UIR

Huliyah, Muhiyatul. 2016. Hakikat Pendidikan Anak Usia Dini. Al-Sibyan, Vol.1, No.1,. Jurnal Pendidikan Guru Raudlatul Athfal ISSN 2541-5549

Iskandar. 2010. Metode Penelitian Kualitatif : Aplikasi untuk Penelitian Pendidikan, Hukum, Ekonomi \& Manajemen, Sosial, Humaniora, Politik, Agama dan Filsafat. Jakarta: Gaung Persada.

Jalal, Fasli. 2004. Seminar dan Lokakarya PAUD menyongsong kurikulum Pendidikan Anak Usia Dini Berbasis Kcerdasan Jamak di masa depan. Jakarta: Depdiknas.

Jasmine, Julia. 2007. Panduan Praktis Mengajar Berbasis Kecerdasan Majemuk; Cet ke-1. Bandung: Nuansa 


\section{GENERASI EMAS}

Jurnal Pendidikan Islam Anak Usia Dini

Vol. 01 No. 02, Oktober 2018

Lwin, May, dkk. 2005. How to Multiply Your Child's Intelligence, Cara Mengembangkan Berbagai Komponen Kecerdasan; Cet-ke1. Jakarta: Indeks.

M. Solehuddin. 2001. Konsep Dasar Pendidikan Pra-sekolah. Bandung: Fakultas Ilmu Pendidikan UPI.

Majid, Abdul \& Andayani, Dian. 2005. Pendidikan Agama Islam Berbasis Kompetensi; Konsep dan Implementasi Kurikulum 2004. Bandung: PT. Remaja Rosdakarya.

Mansur. 2002. Diskursus Pendidikan Islam. Yogyakarta: Global Pustaka Utama.

Mansur. 2015. Pendidikan Anak Usia Dini dalam Islam. Yogyakarta: Pustaka Pelajar Offset.

Martinis, Yamin dan Jamilah, Sanan Sabri. 2012. Panduan PAUD (Pendidikan Anak Usia Dini). Jakarta: Gaung Persada Press Group.

Masitoh. 2014. Hakikat Pendidikan dan Pembelajaran di Taman Kanak-kanak. Strategi Pembelajaran TK. PGTK2202/Modul 1.

Moleong, Lexy J. 2001. Metodologi Penelitian Kualitatif. Bandung: Remaja Rosdakarya.

Muhaimin. 2004. Paradigma Pendidikan Islam dalam Upaya Mengefektifkan Pendidikan Agama Islam di Sekolah. Jakarta: Remaja Rasda Karya.

Muhajir, Neong. 1998. Metodologi Penelitian Kualitatif. Yogyakarta: Rake Sarasin.

Muhammad bin Jarir bin Yazid bin Katsir AlThabary. t.th. Jami' Al-Bayan fi Tafsir Al-Quran, Tafsir Ath-Thabari. Beirut: Dar al-Kutub.
Muhammad Fadhlillah \& Khorida Lilif Mualifatu. 2014. Pendidikan Karakter \& Aplikasi dalam PAUD. Jogjakarta: ArRuzz Media.

Muhammad Nazir. 1997. Metodologi Penelitian. Jakata: Ghalia Indonesia.

Muhammad, Ahsin Sakho, et., all. 2010. AlQur'an dan Tafsirnya. Jakarta: Lentera Abadi.

Mulyana, Dedy. 2005. Metodologi Penelitian Kualitatif. Bandung: Remaja Rosdakarya.

Musbikin, Imam. 2011. Buku Pintar PAUD. Jogjakarta: Laksana.

Musfiroh, Tadkiroatun. t.th. Multiple Intelligences dan Implikasinya dalam Pendidikan. Pusdi PAUD, Lemlit UNY. www.islamis.sources.com.

Nawawi, Hadari. 2009. Metode Penelitian Bidang Sosial. Yogyakarta: Gajah Mada University Press.

Ningrum, Etik Dwi Novita. 2018. Relevansi Kajian Tafsir Surat Al-Luqman Ayat 1219 Terhadap Pendidikan Anak Usia Dini. Program Studi Pendidikan Islam Anak Usia Dini Fakultas Tarbiyah dan Ilmu Keguruan Institut Agama Islam Negeri (IAIN) Salatiga.

Nurhadi. 2018. Konsep Kurikulum Pendidikan Keluarga dalam Surah AlLuqman. Al-Ishlah: Jurnal Pendidikan. ISSN: 2087-9490 (p); 2597-940X (o) Vol. 10, No. 1

Putri, Yeni Sugena. 2016. Pengaruh Kecerdasan Intelektual, Kecerdasan Emosional, dan Lingkungan Kerja Terhadap Kinerja Karyawan PT. PLN Persero Area Klaten. Jurnal Studi Manajemen \& Organisasi 13 Juni.

Raihana. 2018. Urgensi Sekolah Paud Untuk Tumbuh Kembang Anak Usia Dini. 


\section{GENERASI EMAS}

Jurnal Pendidikan Islam Anak Usia Dini

Vol. 01 No. 02, Oktober 2018

Generasi Emas Jurnal Pendidikan Islam

Anak Usia Dini Volume 1 No. 1. Pekanbaru: UIR.

Republik Indonesia. 2003. Undang-undang Nomor 20 Tahun 2003 Tentang Sistem Pendidikan Nasional. Jakarta: Setneg

Satu Warna. 2012. Al-Hadi Mushhaf Latin. Tafsir Perkata. Kode Tajwid latin. Transliterasi Latin. Asbab Nujul. Tematik. Penjelasan Ayat. Doa alQur'an. Jakarta: Insan Media Pustaka.

Sayyid Quthb. 2014. Tafsir fi Zhilalil Qur'an, Terj. As'ad Yasin dan Abdul Aziz Salim basyarahil. 2012. Di Bawah Naungan AlQuran. Jakarta: Gema Insani Press. Jilid XXI.

Setyaningrum, Ayu. 2015. Tafsir Surat Luqman Ayat 12-19 Tentang Pendidikan Anak Menurut Muhammad Quraish Shihab dan Mahmud Yunus (Studi Komparasi). Semarang: Fakultas Ushuluddin dan Humaniora Universitas Islam Negeri (UIN) Wali Songo.

Shihab, M. Quraish. 2010. Tafsir AlMishbah, Pesan, Kesan dan Keserasian Al-Qur'an, Vol. 10. Jakarta: Lentera Hati.

Stheppe,n Robbins P .2001. Perilaku Organisasi. Edisi Bahasa Indonesia. Jakarta: PT. Indeks. Terjemahan $\mathrm{Ti} \mathrm{m}$ Indeks, Jilid II.

Suarca, Kadek, Soetjiningsih, IGA., Ardjana, Endah. 2005. Kecerdasan Majemuk pada
Anak. Sari Pediatri, Vol. 7, No. 2, September 2005

Suharsono. 2004. Mencerdaskan Anak, Melejitkan Intelektual dan Spritual, Memperkaya Hasanah Batin, Kesalehan serta Kreativitas Anak (IQ, EQ dan SQ, Cet: ke-1. Depok: Inisiasi Press.

Sujiono, Yuliani Nurani. 2010. Konsep Dasar Pendidikan Anak Usia Dini. Jakarta: Indeks.

Sulaiman ibn al-Asy'ats ibn Ishaq ibn Bisyr ibn Syaddad ibn 'Amr ibn 'Imran, Abu Dawud al-Azdi as-Sijistani. t.th. Shahih Sunan Abu Daud. Lebanon: Dar alHadis.

Suprayogo, Imam dan Tobroni. 2002. Metodologi Penelitian Sosial-Agama. Bandung: Remaja Rosdakarya.

Suryana, Dadan. 2014. Dasar-dasar Pendidikan TK. PAUD 4107/Modul 1

Tomi, Nhera. 2015. Kecerdasan. Makalah artikel online diwibesite http://neratomi.blogspot.com/2015/06/m akalah-kecerdasan.html.diakses 28 oktober 2018 jam 20.00 wib.

Wahyuni, Ida Windi. 2018. Penerapan NilaiNilai Moral Pada Santri TPQ AlKhumaier Pekanbaru. Generasi Emas Jurnal Pendidikan Islam Anak Usia Dini Volume 1 No. 1. Pekanbaru: UIR.

Wibowo, Agus. 2012. Pendidikan Karakter Usia Dini. Yogyakarta: Pustaka Pelajar. 